\title{
Machiavellian emotion regulation in a cognitive reappraisal task: An fMRI study
}

\author{
Anita Deak ${ }^{1} \cdot$ Barbara Bodrogi $^{1} \cdot$ Brigitte Biro $^{1} \cdot$ Gabor Perlaki $^{2} \cdot$ Gergely Orsi $^{2}$. \\ Tamas Bereczkei ${ }^{1}$
}

Published online: 19 January 2017

(C) Psychonomic Society, Inc. 2017

\begin{abstract}
Affective coldness is one of the main features of Machiavellianism. Recent studies have revealed that Machiavellians are emotionally detached and that this "affective blunting" is associated with intense feelings, emotional instability, negative emotions, and difficulty in enduring distress. We used brain-imaging techniques to investigate emotion regulation in Machiavellianism at a neuropsychological level. We used situations in which participants were required to demonstrate emotional flexibility to explore the controversy surrounding the fact that Machiavellianism is associated with both cold-mindedness and emotional instability. Participants performed a reappraisal task in which emotionally evocative pictures (from the International Affective Picture System) were presented in different contexts (negative, positive, and neutral). They were asked to interpret a scenario according to its title and to reinterpret it according to another context created by a new title (e.g., negatively labeled pictures shifted to positively labeled ones). During task performance, Machiavellians showed increased activation of brain regions associated with emotion generation - for example, the amygdala and insula. This indicates that Machiavellian individuals are able to be involved emotionally in social situations. Increased activation in the temporal and parahippocampal regions during reappraisal suggests that Machiavellians use semantic-perceptual processes to construct alternative interpretations of the same situation and have enhanced memory for
\end{abstract}

Anita Deak

deak.anita@pte.hu

1 Institute of Psychology, University of Pécs, Ifjúság Str. 6, Pécs H-7624, Hungary

2 MTA-PTE Clinical Neuroscience MR Research Group, University of Pécs, Pécs, Hungary emotional stimuli. Furthermore, they seem to possess an intense awareness that leads them to shift attention from external to internal information to detect environmental changes. These cognitive processes may enable them to adjust their behavior quickly. This study supports the flexibility hypothesis of Machiavellianism and suggests that Machiavellians' approach to emotion regulation is linked to their rational mode of thinking.

Keywords Machiavellianism $\cdot$ Reappraisal $\cdot$ Emotion regulation · Flexibility · IAPS · Superior temporal gyrus · Insula $\cdot$ Amygdala

\section{Cognitive appraisal}

Different authors have used different definitions of the term "emotion regulation" (Gross, 1998, 2002, 2014; Jackson, Malmstadt, Larson, \& Davidson, 2000; Thompson, 1994). Gross $(1998,2002,2014)$ put forward a process model of emotion regulation in which it is conceived as a "process by which individuals influence which emotions they have, when they have them, how they experience and express these emotions" (Gross, 1998, p. 275). In this model, the two main types of emotion regulation processes are antecedent- and response-focused emotion regulation.

Antecedent-focused regulation occurs during the early stage of emotional processing, whereas response-focused processes come into play in the later stage and are involved in the regulation of already-evoked emotion. Cognitive change or cognitive reappraisal (reframing) is an antecedent-focused strategy; it involves changing one's thoughts about an event. Reinterpretation of the event results in emotion regulation, and thus alters meaning of the event. Cognitive reappraisal is often used to decrease the magnitude of an emotional 
response, but it can also increase it. Cognitive reappraisal occurs at a relatively early stage via cognitive-control processes; it is an effective method of regulating emotional state and behavior and contributes to psychological and physical wellbeing (Gross, 1998, 2002).

Emotion regulation can occur at the quantitative or qualitative level. Qualitative change involves the attribution of a new meaning to a situation (reinterpretation), and the valence of the emotions evoked by the situation may change, for example, from unpleasant to pleasant. An everyday example would be the regulation of emotions in response to organizational change in a company; initially this might be interpreted as frightening, and employees might be stressed or worried about the new arrangements, or they might be sad to lose colleagues or their position. After reappraisal, employees might see the organizational changes as a good, rational strategy for saving money and preserving jobs. Emotion regulation may also involve a change in the intensity of an affective state. In summary, emotion regulation can modify the intensity of an emotion, change its duration, or change the nature or quality of the emotion involved. There are many examples of adaptive emotion regulation strategies: for instance, minimizing the effect of negative emotions, maximizing the impact of positive emotions, taking control of emotions by delaying action, or creating and maintaining long-term goals (Lee, Heller, van Reekum, Nelson, \& Davidson 2012; Ochsner et al., 2004; Thompson, 1994).

\section{Neural background}

Cognitive reappraisal is defined as an emotion regulation process in which one changes what one thinks about a stimulus to change the affective state it elicits. Some researchers have found that prefrontal and parietal brain regions are involved in the cognitive control of other brain regions related to emotional responses, such as the amygdala. Others have pointed out that control regions (e.g., the prefrontal network) modulate semantic representations in the temporal cortex (Buhle et al., 2014; Etkin, Büchel, \& Gross 2015).

Researchers have agreed that three brain structures play crucial roles in cognitive reappraisal (Ochsner, Silvers, \& Buhle 2012): the ventrolateral prefrontal cortex (VLPFC; Badre \& Wagner, 2007; Thompson-Schill, Bedny, \& Goldberg 2005), the dorsolateral prefrontal cortex (DLPFC; Miller \& Cohen, 2001; Phan, Wager, Taylor, \& Liberzon 2002), and the anterior cingulate cortex (ACC; Botvinick, Cohen, \& Carter 2004).

Four brain structures are involved in the control functions relevant to cognitive reappraisal (Ochsner et al., 2012): the ventromedial prefrontal cortex (VMPFC; Badre \& Wagner, 2007; Roy, Shohamy, \& Wager 2012), the amygdala (Cunningham \& Brosch, 2012; Cunningham, Van Bavel, \&
Johnsen 2008; Hariri \& Whalen, 2011), the ventral striatum (Knutson \& Cooper, 2005; O'Doherty, 2004), and the insula (Craig, 2009; Chang, Yarkoni, Khaw, \& Sanfey 2013; Zaki, Davis, \& Ochsner 2012).

Functional magnetic resonance imaging (fMRI) studies of emotional responses have shown that pleasant stimuli activate the medial dopaminergic regions (ventral striatum, nucleus accumbens), hypothalamic areas, VMPFC, and the right orbitofrontal cortex (OFC), whereas unpleasant stimuli activate the amygdala, anterior insula, and left OFC (Wager, Davidson, Hughes, Lindquist, \& Ochsner 2008). The VMPFC also regulates negative affect by modulating the amygdala (Diekhof, Geier, Falkai, \& Gruber, 2011, Buhle et al., 2014).

Reappraisal of the valence of an emotional stimulus depends strongly on the left hemisphere, and reappraisal of negative emotions requires more cognitive capacity than does the processing of positive emotions. Reappraisal also increases activity of the right lateral prefrontal cortex (PFC; Aron, Robbins, \& Poldrack 2014; Ochsner et al., 2012), which is responsible for response inhibition and selection. Positive and negative reappraisals have different effects on activity in the following areas: medial PFC, ACC, the precuneus, and the superior parietal lobule (van Reekum et al., 2007).

The amygdala is often mentioned in relation to emotion regulation. For example, amygdala gray-matter volumes were found to be positively correlated with cognitive reappraisal and expressive suppression and with neuroticism, used as an indicator of general negative emotionality (Hermann, Bieber, Keck, Vaitl, \& Stark 2014). Positive reappraisal is associated with activation of the caudate nucleus and the right OFC. The caudate nucleus plays an important role in reward processes and positive information processing, whereas the $\mathrm{OFC}$ is involved in the appraisal of rewarding stimuli (O’Doherty, 2004).

\section{Machiavellianism}

Machiavellians - individuals who have high scores on Mach scales (Christie \& Geis, 1970) - display a specific emotion regulation style. One of the main features of this style is a kind of affective detachment: Machiavellians detach themselves emotionally from situations and lack emotional involvement with others (Austin, Farrelly, Black, \& Moore 2007; Christie $\&$ Geis, 1970). They are strongly motivated by the strategic consequences (e.g., immediate reward) of behavior and are not distracted by affect (Geis, Weinheimer, \& Berger 1970; Wilson, Near, \& Miller 1996). Some authors argue that Machiavellians' manipulative abilities are derived from superior impulse regulation (Jones \& Paulhus, 2009). A recent study has suggested that Machiavellianism is a predictor of several psychopathological constructs (depression, anxiety, impulsivity, etc.), and that the use of Machiavellian tactics is 
related to externalizing disorders (Monaghan, Bizumic, \& Sellbom 2016).

Machiavellians use long-term strategies related to flexibility and planning (Bereczkei, 2015). They are constantly evaluating the social situation and their partners, and they adjust their behavior according to changing circumstances. Their emotion regulation may be closely linked to their flexible decision making, in that they are able to control their emotional responses and inhibit moral compunction.

Machiavellianism has been found to be negatively correlated with self-report and performance-based measures of emotional intelligence (emotion management, sensations, emotional relations, etc.; Austin et al., 2007). People with high Mach scores are less capable of subtle, nuanced expression of emotions than are those with lower scores (Ali, Amorim, \& Chamorro-Premuzic 2009; Austin et al., 2007: Paal \& Bereczkei, 2007; Pilch 2008; Szijjarto \& Bereczkei, 2015). They display a lack of emotional sensitivity and show deficits in understanding emotions (Nagler, Reiter, Furtner, \& Rauthmann 2014). It is not surprising that Machiavellianism has been associated with alexithymia, an impairment in the ability to identify and verbalize one's feelings (Wastell \& Booth, 2003). Although their impaired ability to express emotions may be seen as a deficit, it may help them to deceive and manipulate others, by making it easier for them to conceal their emotions and intentions (Mcllwain, 2003; Szijjarto \& Bereczkei, 2015). This notion is supported by evidence that Machiavellians experienced positive affect toward sad emotions, thus showing affective desensitization to and discordance with such stimuli (Wai \& Tiliopoulos, 2012).

Recent studies have revealed, however, that in Machiavellians this kind of "affective blunting" is frequently associated with intense feelings. Machiavellianism was found to be positively associated with neuroticism variables, indicating that Machiavellians tend to be emotionally unstable (Szijjarto \& Bereczkei, 2015). As compared with people with lower Mach scores, they may experience more negative emotion, lose their temper more easily, and have greater difficulty enduring distress. It is possible that Machiavellians find emotionally stressful situations more fatiguing than other people do; this would contradict the widespread perception that they are cold, rational thinkers. It has also emerged that Machiavellians are not deficient in all aspects of emotional intelligence. They are capable of using emotional manipulation to obtain an advantage, which indicates that they can successfully use emotion-related tactics to mislead others (Austin et al., 2007). Furthermore, if the agreeableness components of emotional intelligence (such as optimism, positivity, and inclination to help) are excluded, there is actually a positive relationship between Machiavellianism and emotional intelligence, which suggests that high-Mach people have high emotional competence, but that it is strongly selffocused (O’Connor \& Athota, 2013).
There have been several fMRI studies of Machiavellians' responses to various social contexts. As compared with lowMach people, they showed increased neural activation of the right anterior insula and right inferior frontal gyrus, which are involved in responses to emotional and stressful situations (Bereczkei, Deak, Papp, Perlaki, \& Orsi 2013). Another study found elevated anterior DLPFC activity in Machiavellians; this region is thought to be responsible for the cognitive control of prepotent emotional responses (Bereczkei et al., 2015). A structural magnetic resonance imaging study revealed differences between people with high and low Mach scores in the basal ganglia (a reward center), left PFC (regulation of negative feelings), and insula (suppression of negative emotions; Verbeke et al., 2011).

High-Mach people have higher scores on the Neuroticism scale, which raises the question of how neuroticism is related to reappraisal. Several studies have shown that neuroticism may effect emotion regulation and reappraisal, and that it is linked to certain brain structures, namely the amygdala and the dorsal part of the ACC (Hermann et al., 2014). Amygdalar and DLPFC activity when viewing unpleasant pictures designed to elicit an emotional response has been shown to be positively correlated with neuroticism (Harenski, Kim, \& Hamann 2009). Similarly, psychopathy - usually considered a clinical form of Machiavellianism - was negatively correlated with amygdala activity in response to unpleasant pictures. This result corroborated previous studies showing that low emotional reactivity and cold-heartedness are the main components of psychopathy and Machiavellianism (Szijjarto \& Bereczkei, 2015).

\section{Hypotheses}

Brain-imaging techniques could be used to examine the above-mentioned controversies about Machiavellians' emotion regulation - cold-mindedness versus high emotional instability; low emotional intelligence versus skilled manipulation of others' emotions - on a neural level. Mapping the neural regions involved, and measuring neural activity during an emotion-processing task should help us to understand how Machiavellians handle their emotions and how they apply them in a particular situation. In this experiment, emotionally evocative pictures (drawn from the International Affective Picture System [IAPS]) were interpreted in different contexts (i.e., negative, positive, and neutral). Participants performed a reappraisal task and had to provide different interpretations of the presented pictures according to the changed emotional athmosphere created by different titles (e.g., negatively labeled pictures shifted to positively labeled ones). We measured how flexibly and appropriately participants reinterpreted the pictures and related this to Mach score and to the patterns of neural activity that participants displayed when responding. 
In line with recent findings suggesting that Machiavellians do experience intense emotions, we expected to observe differences between the behavioral outputs of the low-Mach and high-Mach groups in terms of their overall ratings of the valence and arousal for the pictures. Specifically, we predicted that Machiavellians would, on average, have higher arousal scores than non-Machiavellians. We also predicted that the high- and low-Mach groups would show different patterns of neural activity during this task. On the basis of previous fMRI studies, we hypothesized that the high-Mach group would show increases in amygdalar and cingulate activity during the cognitive reappraisal process.

\section{Method}

\section{Participants}

Participants were selected from a population of more than 600 young volunteers (university students) who had filled out some preliminary questionnaires and agreed to take part in further research. The selection was based on scores on the Mach-IV scale (Christie \& Geis, 1970), and two groups were defined on the basis of \pm 1 standard deviation from the group mean. The upper limit for participation in the low-Mach group was 90, and the lower limit for participation in the high-Mach group was 110. An official invitation letter was e-mailed to potential participants with scores in the required range. We deliberately excluded people with average Mach scores from the sample.

Thirty-eight healthy university student volunteers (17 men, 21 women; mean age $=21.46$ years, $S D=2$ years) met all of the criteria and participated in this study. Participants were categorized as either low-Mach (LM) or high-Mach (HM). The LM group consisted of 20 participants (nine men, 11 women) with a mean Mach-IV score of $80(S D=5.52$; minimum 72, maximum 89). The HM group consisted of 18 people (eight men, ten women) with a mean Mach-IV score of 122.03 ( $S D=9.95$; minimum 111, maximum 145). None of the participants had any psychiatric or neurological disorder, and all but two were right-handed. Handedness was treated as a covariate in the analysis.

\section{Measures}

Machiavellianism (Mach-IV scale) We used the 20-item Mach-IV Scale (Christie \& Geis, 1970) to measure individuals' tendency to manipulate and deceive other people for personal gain. Responses are given using a seven-point Likert scale $(1=I$ do not agree at all to $7=$ I fully agree; total score range: 20-140). Higher scores indicate a more Machiavellian thinking style and a greater tendency to behave misleadingly in interpersonal relationships.
Emotional stimuli (IAPS pictures) The visual stimuli were selected from the Hungarian standardized database (Deak, Csenki, \& Revesz 2010) of the IAPS (Lang, Bradley, \& Cuthbert 2005). These colorful, emotionally evocative pictures can be evaluated on three affective dimensions: valence (pleasant or unpleasant), arousal (calm or excited), and the extent to which the affective state evoked by the images is controllable (low scores indicate that the image evokes emotions that overwhelm the respondent; high scores indicate that the respondent feels he or she can control the emotions evoked).

Reappraisal task We selected IAPS pictures depicting social situations for the reappraisal task; the main consideration was whether an image was capable of being interpreted in several ways.

A pilot study was carried out to select a suitable set of images. First, we selected about 50 IAPS pictures depicting social scenes and people displaying various affective states (e.g., sadness, anger), on the basis of the Hungarian standard ratings (Deak, Csenki, \& Revesz 2010).

We showed each picture to a sample of young volunteers (same age and education profile as the sample for this study) and asked them to give the picture a title and tell a short story about the scene and characters. Then we instructed them to reinterpret the picture, give it another title and tell another story. This procedure yielded two different interpretations per picture for each pilot participant.

We summarized the stories and titles, and we selected those titles that were mentioned with the highest frequency. As a result, we had 15 pairs of pictures with two different titles. Another group of young people rated how well these titles fitted the pictures. The results showed that all the titles were considered highly appropriate for the pictures, although the two titles for a given picture prompted two different interpretations.

On the basis of the pilot study, we constructed a stimulus set of 15 pictures and assigned two titles (keywords) to each. The first title was the title that had been most frequently assigned to that picture in the first phase of the pilot study (IAPS1), and the second title was the second-mostfrequently assigned title (IAPS2). The two titles evoked two interpretations and implied different emotional contexts for the same picture. The pictures were presented in pairs: Each picture was shown twice, with the two different titles, one after another. The sequence of titles was random: positive to negative in three cases (pictures 5629, 2616, 9421), negative to positive in four cases $(2480,6530,8010,4598)$, negative to neutral in five cases $(6825,9050,6250,6212,6360)$, and neutral to neutral in three cases $(2691,6836,9102)$. For example, a hugging couple was first presented with the title "Farewell" (IAPS1; negative) and then with the title 
"Meeting again" (IAPS2; positive). Participants were asked to interpret each picture on the basis of the title, imagining it as a real-life situation, empathizing with the characters and giving way to their emotions. We called participants' attention to the fact that they would see each picture with two different titles (the first and second presentations; IAPS1 and IAPS2) that suggested different interpretations. Constructing two different interpretations of the same visual stimulus required participants to reappraise the stimulus.

\section{Procedure and experimental paradigm}

The experimenter instructed the participants individually before the scanning session. Each participant was given the opportunity to practice the reappraisal task to ensure that he or she understood the instructions. In the practice session, we presented pairs of pictures with two different titles one after another on a laptop screen, as they would be presented in the experimental session.

Four conditions were used were used in the experiment: IAPS1, IAPS2, CONTROL1, and CONTROL2 (see Fig. 1). In the IAPS1 condition, the stimulus was presented with the first title. In the IAPS2 condition, the same picture was presented with the second title. The CONTROL1 condition was a black screen displaying the instruction "RELAX" in white. The CONTROL2 condition used a layout similar to that in the IAPS1 and IAPS2 conditions, but a scrambled version of the experimental stimulus was presented, in which the picture was unrecognizable, and the title was a meaningless letter string.

During scanning, the participant's task was to focus on the pictures on the screen and to let the feelings and thoughts evoked by the titles flow freely. Behavioral data were collected after the scanning procedure.

Each stimulus presentation lasted $8 \mathrm{~s}$. This duration was chosen on the basis of pilot studies. The experiment started with an 8-s presentation of an introductory screen informing the participant that "The experiment starts soon." This was followed by 60 experimental trials $(4 \times 15)$.

We started with an 8-s presentation of the CONTROL2 image. This was followed by the IAPS1 stimulus $(8 \mathrm{~s})$, then the CONTROL1 image $(8 \mathrm{~s})$, and the second presentation of the picture, IAPS2 $(8 \mathrm{~s})$. The whole design ended with an 8 -s presentation of the CONTROL2 image. In total, 244 scans were recorded [INTRO $(8 \mathrm{~s})+\operatorname{IAPS} 1(15$ pictures $\times 8 \mathrm{~s})+$ IAPS2 $(15 \times 8 \mathrm{~s})+$ CONTROL1 $(15 \times 8 \mathrm{~s})+$ CONTROL2 $(15$ $\times 8 \mathrm{~s})$ ]. The duration of the examination was $8 \min 8 \mathrm{~s}$.

\section{Behavioral data}

After the MRI examination, participants filled in a posttest questionnaire to provide behavioral data. They were asked to rate the pictures they had seen during the scanning session on the following dimensions: (1) pleasantness (valence), (2) intensity (arousal), and (3) difficulty of reframing (how difficult it was to switch from one context to another-i.e., from IAPS1 to IAPS2). The responses were given using ninepoint Likert scales $(1=$ unpleasant to $9=$ pleasant; $1=$ low intensity to $9=$ high intensity; $1=$ easy to reappraise to $9=$ difficult to reappraise). We also asked participants to recall the picture contexts they had seen during the scanning session and to write down a short story or description for each stimulus.

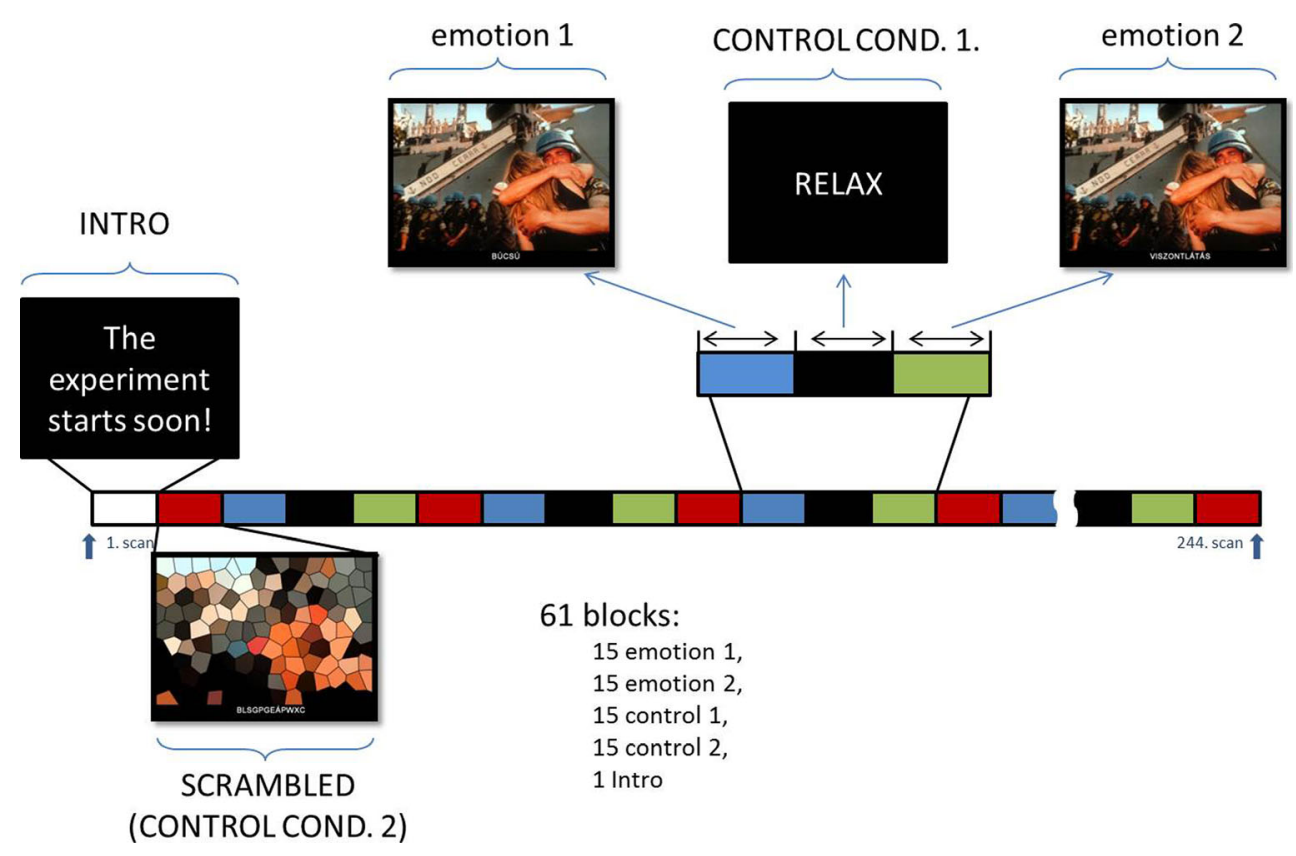

Fig. 1 Experimental design 
We used an independent-samples $t$ test (IBM SPSS version 22) to compare the reappraisal difficulty ratings of the HM and LM groups for all the 15 pictures.

We conducted separate 2 (Timing: before and after appraisal) $\times 2$ (Group: HM; LM) ANOVAs with valence and arousal as dependent variables to test our hypothesis about Machiavellian emotion generation processes and flexibility (for descriptive statistics, see Table 1 ). We used $p<.05$ statistical threshold for the analyses of the behavioral data.

We calculated the difference between the self-reported valence ratings before and after reappraisal, and defined two directions of emotion regulation for the fMRI analysis: (1) when the task started from a negative emotion and the participants reappraised to a positive one (upward regulation) and (2) when the first context was positive and the participants interpreted it according to a negative title (downward regulation).

\section{Functional MRI data acquisition and analysis}

MRI data were acquired with a 3-T scanner (MAGNETOM Trio, Siemens AG, Erlangen, Germany) at the Diagnostic Center of Pécs (Pécs, Hungary) equipped with a 12-channel head coil. Functional MRI was based on a gradient-echo echoplanar imaging sequence $(\mathrm{TR}=2,000 \mathrm{~mm}, \mathrm{TE}=36$ $\mathrm{ms}$, flip angle $=76^{\circ}, \mathrm{FOV}=230 \mathrm{~mm} \times 230 \mathrm{~mm}$, matrix $=$ $92 \times 92, \mathrm{ST}=4 \mathrm{~mm}$, no gap) with a spatial resolution of $2.5 \times$ $2.5 \times 2.5 \mathrm{~mm}$ (23 slices with interleaved slice order) in an axial orientation parallel to the AC-PC plane. Motion correction was according to the manufacturer's instructions. Image processing was carried out using SPM5 (www.fil.ion.ucl.ac. $\mathrm{uk} / \mathrm{spm}$ ) implemented in MATLAB (Version 7.0.1.24704 [R14] Service Pack 1) (Mathworks Inc., Sherborn, MA). Images were corrected for motion, registered to the standard space at $2 \times 2 \times 2 \mathrm{~mm}$, normalized to the SPM5 template, and smoothed with a full-width-at-half-maximum Gaussian kernel of $5 \mathrm{~mm}$.

The fMRI analysis focused on the group differences in valence-specific emotion regulation. The aim was to examine the pattern of neural activity associated with upward and downward changes in emotional valence and to test the flexibility hypothesis. First, we used participants' self-reported valence ratings to identify pictures for which they had used up- and down-regulation strategies. We computed a first-level, subject-wise analysis using a general linear model with a hemodynamic response function modeling the reappraisal mechanism. The following regressors were used to define the design matrix: (1) IAPS1 (before reappraisal), (2) IAPS2 (after reappraisal), (3) CONTROL1 ("relax" instruction), and (4) CONTROL2 (scrambled image). We defined the IAPS2IAPS 1 contrast for all 15 pictures for each participant, and a first-level analysis was computed by modeling the up- and down-regulation of emotional valence. As a second-level analysis, we used independent-sample $t$ tests for comparing LM versus HM activity during the up- and down-regulatory reappraisals, respectively. Small-volume correction was performed $\left(p_{\mathrm{FWE}}<.05, r=3 \mathrm{~mm}\right)$.

\section{Results}

\section{Behavioral results}

Participants were instructed to rate the valence and arousal associated with each picture presentation and the difficulty of reinterpreting at the second presentation of an image. The HM and LM groups provided similar reappraisal difficulty ratings.

Table 1 Valence, arousal, and reappraisal difficulty ratings before (IAPS1) and after (IAPS2) cognitive reappraisal for high-Mach and low-Mach groups

\begin{tabular}{|c|c|c|c|c|c|}
\hline & & \multicolumn{2}{|c|}{ Low-Mach Group } & \multicolumn{2}{|c|}{ High-Mach Group } \\
\hline & & $\begin{array}{l}\text { Before } \\
\text { Reappraisal }\end{array}$ & $\begin{array}{l}\text { After } \\
\text { Reappraisal }\end{array}$ & $\begin{array}{l}\text { Before } \\
\text { Reappraisal }\end{array}$ & $\begin{array}{l}\text { After } \\
\text { Reappraisal }\end{array}$ \\
\hline \multirow[t]{3}{*}{ All pictures } & Valence & 3.44 & 5.47 & 3.56 & 5.27 \\
\hline & Arousal & 7.03 & 6.84 & 6.49 & 6.33 \\
\hline & Difficulty & 3.92 & & 3.68 & \\
\hline \multirow[t]{3}{*}{ Down-regulation } & Valence & 7.45 & 2.75 & 7.17 & 2.63 \\
\hline & Arousal & 7.18 & 6.37 & 6.65 & 7.09 \\
\hline & Difficulty & 4.38 & & 3.69 & \\
\hline \multirow[t]{3}{*}{ Up-regulation } & Valence & 2.64 & 7.7 & 2.53 & 7.44 \\
\hline & Arousal & 6.46 & 6.89 & 6.99 & 6.72 \\
\hline & Difficulty & 3.39 & & 3.7 & \\
\hline
\end{tabular}




\section{Ratings of emotional valence during the reappraisal task}

In the case of down-regulatory reappraisals, we found a difference between the valence ratings for the first and the second presentations of a picture (IAPS1: $M=7.31, S D=1.14$; IAPS2: $M=2.69, S D=1.04 ; F=298.94, p<.001)$. No difference was apparent between the LM and HM groups ( $F$ $=0.73, p>.05)$, nor an interaction between group and presentation position $(F=0.09, p>.05)$.

The results were similar for upward reappraisals. Valence ratings for the first and second presentations were different $(F$ $=487.91, p<.001)$. The mean rating of the negative presentation was $2.58(S D=0.86)$, and this increased to $7.57(S D=$ $1.03)$ for the positive presentation. No group difference emerged $(F=0.104, p>.05)$, nor an interaction between group and presentation position $(F=0.74, p>.05)$.

\section{Ratings of emotional arousal during the reappraisal task}

In the case of down-regulatory reappraisals, there was an interaction between presentation position and group with respect to the arousal ratings $(F=7.89, p<.01)$. LM participants reported a decrease in arousal $[t(19)=2.39, p<.05]$ when the positive presentation occurred first. At the first presentation, the mean arousal rating was $7.18(S D=1.12)$, and at the second, negative presentation, the mean arousal rating was
$6.37(S D=1.47)$. In the HM group, the mean arousal rating for the first, positive presentation was $6.65(S D=1.37)$, and the second, negative presentation elicited a similar arousal rating $(M=7.09, S D=1.25)[t(17)=-1.57, p>.05]$.

In the upward reappraisals, we observed a marginal interaction between group and presentation position $(F=3.06, p=$ .09). The task increased the arousal level for LM participants $\left(M_{n e g \text { pic }}=6.46, S D=1.29 ; M_{\text {pos pic }}=6.89, S D=1.26\right)$, whereas the mean arousal ratings of the HM group were $6.99(S D=1.33)$ for the first, negative presentation and 6.72 $(S D=1.09)$ for the second, positive presentation.

\section{Functional MRI results}

As compared with the LM group, during down-regulatory reappraisals the HM group showed elevated activation of the cuneus and left hippocampus. During upward reappraisals, the HM group showed an increased neural response in the cuneus, left middle temporal gyrus, right fusiform gyrus, right superior temporal gyrus (STG), left parahippocampal gyrus, left posterior cingulate gyrus, left cerebellum, right insula, and amygdala (see Table 2 and Fig. 2). An additional analysis was conducted and showed that the task activated the regions involved in emotion regulation (see the supplementary material).

Table 2 Significant neural activation clusters for the upwards and downwards reappraisals: comparison of high and low Mach groups

\begin{tabular}{|c|c|c|c|c|c|c|}
\hline \multirow[t]{2}{*}{ Brodmann area } & & \multirow{2}{*}{$\begin{array}{l}\text { Number } \\
\text { of voxels }\end{array}$} & \multirow[t]{2}{*}{$t$-statistic } & \multicolumn{3}{|c|}{ Voxel coordinates (MNI) } \\
\hline & & & & $\mathrm{x}$ & $\mathrm{y}$ & $\mathrm{z}$ \\
\hline \multicolumn{7}{|c|}{$\begin{array}{l}\text { Group comparison }(H M>L M) \\
\text { Down-regulatory reappraisal }^{a}\end{array}$} \\
\hline L Cuneus & BA 19 & 10 & 3.65 & -12 & -92 & 36 \\
\hline R Cuneus & BA $18 / 19$ & 30 & 3.89 & 8 & -80 & 28 \\
\hline L Hippocampus & & 7 & 3.6 & -28 & -24 & -12 \\
\hline \multicolumn{7}{|c|}{$\begin{array}{l}\text { Group comparison }(H M>L M) \\
\text { Up-regulatory reappraisal }^{a}\end{array}$} \\
\hline L Cuneus & BA 19 & 7 & 3.84 & -10 & -86 & 36 \\
\hline R Cuneus & BA $18 / 19$ & 57 & 4.02 & 6 & -86 & 24 \\
\hline R Fusiform gyrus & BA 37 & 18 & 3.96 & 40 & -46 & -14 \\
\hline L Middle temporal gyrus & BA 21 & 8 & 4.18 & -58 & -4 & -24 \\
\hline R Superior temporal gyrus & BA 22 & 7 & 4.36 & 38 & -56 & 16 \\
\hline L Parahippocampal gyrus & BA 36 & 46 & 4.09 & -20 & -38 & -18 \\
\hline R Insula & BA 13 & 10 & 3.83 & 46 & -42 & 18 \\
\hline L Posterior cingulate gyrus & BA 31 & 6 & 3.62 & -8 & -68 & 14 \\
\hline R Amygdala & & 6 & 3.64 & 28 & -10 & -16 \\
\hline L Cerebellum & & 18 & 3.84 & -4 & -48 & -14 \\
\hline
\end{tabular}

${ }^{\mathrm{a}}$ Independent sample $t$-test on the second level comparing LM and HM groups, $p_{\mathrm{FWE}}<.05$ (Small Volume Correction, $\mathrm{r}=3 \mathrm{~mm}$ ); L = Left, $\mathrm{R}=\mathrm{Right}$, BA =Brodmann Area 

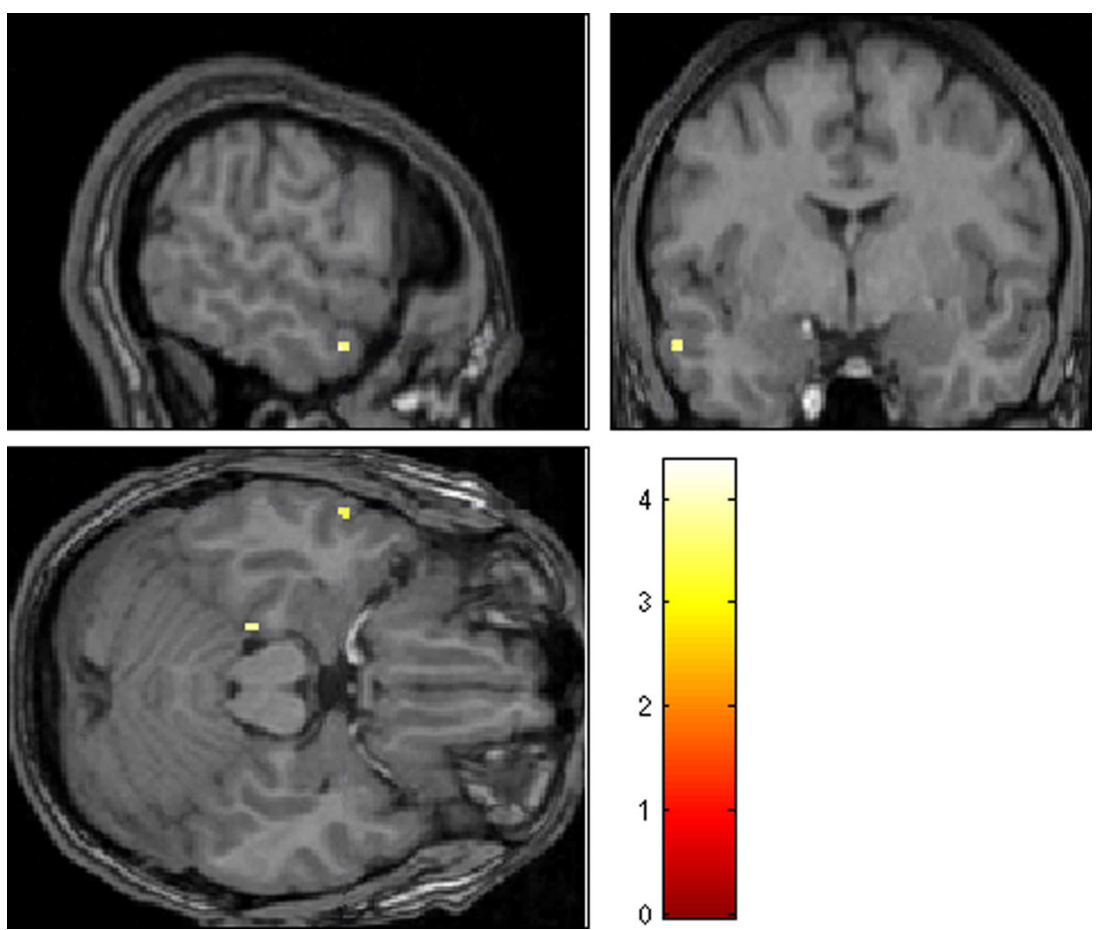

Fig. 2 Activation in the left middle temporal gyrus $(-58-4-24)$ during upward reappraisal $(\mathrm{HM}>\mathrm{LM})$

\section{Discussion}

The aim of this study was to explore the pattern of neural activity underlying the emotion regulatory mechanisms related to Machiavellianism. We found that Machiavellians showed behavioral flexibility in shifting from one emotional context to another. Moreover, direction-specific neural responses were identified when the reappraisal occurred from a positive to a negative or from a negative to a positive emotional context.

\section{Machiavellian emotions: Behavioral output}

Analysis of the posttest valence ratings revealed no difference between the LM and HM groups, but there was a group difference in arousal ratings. Up-regulatory reappraisals prompted an increase in the reported arousal level in the HM group, whereas down-regulatory reappraisals prompted a decrease in reported arousal as compared to LMs. Overall, the HM group reported surprisingly high arousal levels - their scores were in the upper third of a nine-point Likert scale (6.64-7.09) — which may reflect a strong orientation toward the stimuli and intense affective responses to them.

This finding seems to contradict the widespread notion that Machiavellians keep an emotional distance from situations and are incapable of emotional involvement in interpersonal relationships. This study has shown that emotionally loaded pictures elicited intense affective responses in Machiavellians and that altering the emotional label attached to an image modified their subjective arousal levels. This result appears to corroborate recent findings suggesting that Machiavellians do experience intense emotions, and that certain situations may actually evoke even stronger emotions in them than in others (Szijjarto \& Bereczkei, 2015). The intense emotions Machiavellians experience, especially during stress, may contribute to their emotional detachment in situations that offer rewards for breaking norms (Christie \& Geis, 1970). One study reported that Machiavellians experienced negative affect when looking at happy faces (Wai \& Tiliopoulos, 2012). Furthermore, strong feelings may promote fast information processing, spontaneity, and the sense of adventure on which a Machiavellian "first-strike" strategy would depend (Wilson et al., 1996). On the other hand, in spite of their emotional resonance, Machiavellians cannot express their emotions as subtly or accurately as others, and they may be worse at identifying and differentiating their own emotional states (Szijjarto \& Bereczkei, 2015). It is possible that their lack of affective expressivity facilitates behavioral manipulation by minimizing outward signs of anxiety, guilt, shame, and other feelings (McIlwain, 2003).

\section{Direction-independent brain activation pattern}

Both upward and downward reappraisals produced bilateral activation of the cuneus. Previous studies have suggested that the cuneus is mainly involved in visual processing (Goldin 
et al., 2008) and attentional orientation to emotional stimuli (Vetter, Pilhatsch, Weigelt, Ripke, \& Smolka 2015). A recent study showed that the cuneus was active during performance of the emotional Stroop task (Puetz et al., 2016). The cuneus not only plays a role in basic visual processing, but is also involved in social cognition, for instance it is involved in the processing of facial familiarity and identity. This region may also be involved in monitoring emotion as it has been reported that emotional intelligence is negatively correlated with gray matter volume of the left cuneus (Tan et al., 2014).

We assume that monitoring of emotions and monitoring of visual attention processes are linked in the Machiavellians' affective responses. The elevated activation in the cuneus may be due to participants' attending to the emotional content of the pictures. In addition, it may be relevant that we presented social scenes that included depictions of one or more people wearing different emotional facial expressions and using different gestures. Participants may have focused on these social signals (faces and actions of people in the pictures) and interpreted them in light of the title, thus constructing different interpretations of the same scene in response to different contextual cues. Machiavellians seemed to mobilize the visual associative cortical regions (including the cuneus) to analyze social contextual-emotional information contained in the pictures, regardless of the direction of reappraisal.

\section{Direction-specific brain activation pattern}

We also compared the activation maps for the HM and LM groups in two conditions: upward and downward reappraisal.

Downward reappraisal When an image was first presented with a positive title and then re-presented with a negative title, the HM group showed activation of the left hippocampus. The primary functions of the hippocampus are related to memory processing, particularly the encoding and retrieval of episodic memories (Frank et al., 2014; Hamann, 2001). Other studies have expanded its role to encompass social and aesthetic emotions. Trost and Frühholz (2015) linked the hippocampus to attachment anxiety and insecurity. The hippocampus is also involved in the processing of low-arousal affective states such as tenderness, peacefulness and nostalgia. This suggests that the hippocampus activation displayed by the HM group during downward reappraisals may reflect a reliance on memory when a new interpretation is being formed and intensive use of encoding and retrieval mechanisms. Previous studies had shown that some aspects of working memory are superior in Machiavellians (Bereczkei \& Birkas, 2014), specifically the recall of complex or contextual information (Simon, Williams, Wolfe, \& Hessler 2015). Simon et al. presented a video clip to both Machiavellians and non-Machivellians and instructed them to lie or to recount the story accurately. After a oneweek delay, participants were asked to recall some details about the original stimulus material. Machiavellians made fewer recall errors in the "lie" condition. A recent fMRI study (Bereczkei, Deak, Papp, Perlaki, \& Orsi 2013) also suggested that working memory plays a central role in Machiavellians' decision making in social dilemma situations. Machiavellians showed increased bilateral activity in the middle frontal gyrus, a region that plays a role in the manipulation and the active maintenance of information in working memory, which is required for high-level planning. Although these results support the hypothesis that Machiavellians' success is due to their superior information-processing skills and their ability to use behavioral inferences to further their own interest, the question of whether Machiavellians are better at using and recalling emotional information than are non-Machiavellians remains open. Further studies will be required to determine whether Machiavellians' superior sensitivity to their own subjective internal state during emotion regulation is associated with hippocampal activation (Frank et al., 2014).

Upward reappraisal When reappraisal involved shifting from a negative to a positive interpretation, there was increased activity in the middle and superior temporal gyri, parahippocampal gyrus, and posterior cingulate gyrus. Temporal cortical regions are engaged in cognitive reappraisal regardless of the direction (increase or decrease) of the affective response, and these temporal regions are involved in semantic and perceptual encoding (Buhle et al., 2014). The middle temporal gyrus is involved in semantic processing (Tune \& Asaridou, 2016), the processing of complex action-related knowledge (Wallentin et al., 2011), recognition of dynamic facial expressions (Sato, Kochiyama, Yoshikawa, Naito, \& Matsumura, 2004), and social cognition, especially mentalization (Molenberghs, Johnson, Henry, \& Mattingley, 2016).

In line with earlier findings, our results suggest that highMach individuals make intensive use of semantic and perceptual processing when they form new representations that take account of the changing context. This information-processing advantage may help them exploit others to obtain large final payoffs and to adjust their decisions to take account of others' actions (Bereczkei et al., 2013; Bereczkei \& Czibor, 2014). Our findings corroborate an earlier study showing that the middle temporal gyrus is responsible for emotional distancing from negatively valenced pictures (Veit et al., 2012), showing that Machiavellians can remain detached from emotionally arousing stimuli as they reappraise and reinterpret them.

We also found an increase in activity in the Machiavellians' STG. The STG has been linked to language processing, higher-order visual processing, multimodal integration, affective arousal modulation (via the amygdala), and verbalization of mental imagery (Kohn et al., 2014), and it also plays a role in emotional distancing from negative pictures in a downregulation task (Veit et al., 2012). We suggest that the STG 
activation is connected to Machiavellians' efforts to use the contextual title to guide the creation of a new representation of the picture, by mobilizing relevant semantic information. In Machiavellians, the presentation of a new picture stimulus in a negative emotional context may activate subcortical emotion generation regions such the amygdala and insula, leading to arousal. When the same picture stimulus is re-presented in a positive context, Machiavellians may form an alternative mental representation of it, using mental imagery to create a new interpretation based on the new title. Furthermore, the alternative meaning can be detached from the original emotional context; subsequently, it can be a useful mechanism of emotional distancing, which is known to be a core feature of Machiavellianism (Christie \& Geis, 1970; Szijjarto \& Bereczkei, 2015; Wai \& Tiliopoulos, 2012).

The left posterior temporal cortex is involved in understanding mental states and reflecting intentions and actions (Buhle et al., 2014). The increase in superior temporal activation may be due to Machiavellians' superior ability to attribute mental states to the characters in the picture, and this information would help them perform the task. Earlier studies have shown that, contrary to expectations, individuals with high Mach scores performed worse on mindreading tests than did those with low Mach scores (Ali, Amorim, \& ChamorroPremuzic 2009; Lyons, Caldwell, \& Shultz 2010; Paal \& Bereczkei, 2007). It is nevertheless possible that Machiavellians have an above-average capacity for certain mentalization processes. Several studies have reported that when making a decision, Machiavellians are more likely than non-Machiavellians to monitor their partners and take their behavior into consideration (Bereczkei \& Czibor, 2014; Czibor \& Bereczkei, 2012). Another study revealed that Machiavellians were particularly good at mentalization tasks related to social manipulation, suggesting that Machiavellians are good mind-readers in social contexts that offer an opportunity to gain by manipulating others (Szabo, Jones, \& Bereczkei 2016). This mental ability may equip Machiavellians with the cognitive and behavioral flexibility needed to adjust their decisions to take account of the actions of others in a particular environment (Bereczkei, 2015).

As have most studies in the field of emotion regulation, we found activation in the insula and right amygdala of highMach individuals. The insula, specially its anterior part, has consistently been linked to emotion generation and ithe ntegration of affective and visceral information (Buhle et al., 2014). It is involved in conscious awareness and the monitoring of pleasant and unpleasant internal states (Craig, 2009; Frank et al., 2014) and in goal-directed cognition (Chang, Yarkoni, Khaw, \& Sanfey 2013). It also plays a role in the detection of salience, relaying affective arousal, and the subjective feelings associated with emotional states that arise during perception (Kohn et al., 2014; Veit et al., 2012). Spitzer and colleagues found that the lateral orbitofrontal cortex and right insula played important roles in Machiavellians' responses to threats of punishment, enabling them to earn a higher profit over the course of the Ultimate game (Spitzer et al., 2007). Presumably Machiavellians rely on knowledge about their internal state when making decisions about risk and profit.

The amygdala is known to play a role in emotional information processing (Veit et al., 2012), specifically in the processing of emotionally arousing stimuli (Frank et al., 2014) and in emotion generation (Kohn et al., 2014). One of the main findings is that frontal and parietal regions modulate amygdala activity (Buhle et al., 2014). Reappraisal generally involves cognitive-control mechanisms that modulate the brain's semantic representation network for emotional information, and these alternative representations may evoke cognitive mechanisms that regulate the amygdala (Buhle et al., 2014). Intentional increase in the affective feeling also activates the amygdala, which is sensitive to emotional intensity (Frank et al., 2014). In light of these findings, our results suggest that the negative titles induced negative feelings in Machiavellians and elicited a response in subcortical emotion generation structures (amygdala and insula). In view of the role of the amygdala in the detection, encoding, and organization of responses to arousing stimuli (Buhle et al., 2014), we suggest that Machiavellians have a lower-than-normal threshold for stimulus-induced arousal and that to avoid becoming overstimulated, they monitor not only their overt behavior but also their internal representations and affective state, flexibly and as necessary.

The high-Mach participants showed a more intense neural response in the left posterior cingulate gyrus. The posterior cingulate gyrus is involved in controlling attention, possibly in maintaining a vigilant attentional state (Leech, Kamourieh, Beckmann, \& Sharp 2011). More precisely, it plays an important role in shifting the focus of attention between external and internal information, especially in situations that require attention to be shifted from external stimuli toward internal thoughts (Cona et al., 2015; Leech \& Sharp, 2014). Other studies suggest that the posterior cingulate gyrus is involved in the retrieval of information, including emotionally relevant information, from long-term memory (Frank et al., 2014; Kim, Daselaar, \& Cabeza, 2010, Pearson, Heilbronner, Barack, Hayden, \& Platt 2011). A meta-analysis of functional imaging studies concluded that, relative to nominally matched, emotionally neutral stimuli, emotional stimuli consistently activate the posterior cingulate gyrus (Maddock, 1999). Subsequent studies have suggested that this activation might reflect an interaction between emotion and memory. In a study in which unpleasant words were matched with neutral words on nonemotional features known to influence memory, posterior cingulate gyrus activation was associated with enhanced memory for emotional stimuli (Maddock, Buonocore, Kile, \& Garrett 2003). 
It is possible that Machiavellians have an enhanced memory for emotional stimuli; that is, they may recall unpleasant or pleasant stimuli more easily than non-Machiavellians. We propose that Machiavellians find it particularly easy to shift their attention from one stimulus to another. It is possible that on our task they recalled the information associated with the first presentation of a picture (whether positive or negative) and then used this information, in the case of the second picture, to reinterpret it. We also propose that the emotional stimulation caused by viewing affectively valenced pictures activates a cognitive network that promotes adaptive behavior. People preserve various memory cues from the past, and these cues bias their attention, determining what environmental stimuli they attend to and hence how well they respond to new situations. Machiavellians appear to be highly skilled in this process. They display a kind of cognitive generalization: They are good at categorizing people, and their knowledge of people allows them to predict how a given type of person is likely to behave in a given situation (Szabo, Jones, \& Bereczkei 2016). When the emotional context changes, they can switch attention immediately. They may infer from both unpleasant and pleasant stimuli, in order to monitor the possible ways of handling the situation rationally and to judge the "type" of a person as a potential victim.

\section{Conclusion}

The results of this study appear to contradict the traditional view of Machiavellians as cold individuals who keep an emotional distance from interpersonal situations. Their subjective arousal was surprisingly high during our task, and during upward reappraisals we found higher activity in the subcortical emotion generation regions (amygdala and insula) in the HM group than in the LM group. Machiavellians may mobilize their semantic knowledge and memory to create a new interpretation of the stimulus. In Machiavellians the new context elicits a marked increase in activity in the temporal cortex and parahippocampal gyrus. As a consequence of reappraisal, their emotional involvement decreases. It may be also a sign of their increasing emotional distance in social scenes.

We suggest that Machiavellians' success in cognitive reappraisal is not due to frontal executive regulatory processes but to the flexible mobilization of semantic information in response to the changing environment. Surprisingly, we did not find activation in the DLPFC and VLPFC, the key modulators of regulation. The lack of this activation, however, suggests that Machiavellian emotion regulation differs from that of other people not in the final, executive step, but in the earlier stages (see the emotional-regulation-processing model of Gross, 1998, 2002, 2014). In the early stage of emotion regulation, Machiavellians experience more intense affective states (related to the amygdala activation) and are more aware of somatosensory information (related to the insula activation). It seems that high-Mach individuals do not have stronger frontal control; instead, they direct more attention toward the stimulus to create an alternative meaning in the semantic representation system in the temporal cortex. This intense work on the internal representations might be accompanied by a reduction in affective arousal. In conclusion, we suggest that the secret of Machiavellian emotion regulation and cold rationality lies not in superior control, but in flexibility and goal-related use of contextual information.

In sum, we conclude that Machivellians are able to generate emotions and use cognitive emotion regulation strategies to decrease the intensity of their affective responses. During reappraisal they make greater use of attentional and memoryrelated processes to create a new interpretation based on the contextual cues. Presumably, they have access to their internal states; however, their emotional expressivity is influenced by the context. Machiavellians' expression of emotion is flexible: If it serves their goal, they might hide their true emotions in some contexts, whereas they will express them in others (Griffiths, 2003, 2004).

\section{Limitations and further research}

There are some important limitations to our study, including methodological limitations. These include the facts that we collected self-report data on arousal and emotional responses after the scanning session and used only a small number of stimuli in the experiment. The task requires cognitive effort from the participants and might be tiring; therefore, a good balance between the number of trials and the stability of the fMRI signal should be found.

Further research should use other emotion regulation tasks that allow participants to select their own reappraisal strategy instead of giving contextual instructions or guidance, as we did. Further studies should also be conducted to clarify how the affective, memory, and reward systems mediate the Machiavellian decision-making processes on which successful manipulation depends.

Machiavellianism is already known to correlate with personality traits such as the behavioral inhibitory and activation systems (Neria, Vizcaino, \& Jones 2016), neuroticism, and emotional intelligence (Szijjarto \& Bereczkei, 2015). Further studies will be necessary to uncover the relationship between Machiavellianism and anxiety.

Author note The present scientific contribution is dedicated to the 650th anniversary of the foundation of the University of Pécs, Hungary, and this work was supported by the Hungarian Scientific Research Fund-OTKA (K 101762, 112673). 


\section{References}

Ali, F., Amorim, I. S., \& Chamorro-Premuzic, T. (2009). Empathy deficits and trait emotional intelligence in psychopathy and Machiavellianism. Personality and Individual Differences, 47, $758-762$.

Aron, A. R., Robbins, T. W., \& Poldrack, R. A. (2014). Inhibition and the right inferior frontal cortex: One decade on. Trends in Cognitive Sciences, 18, 177-185. doi:10.1016/j.tics.2013.12.003

Austin, E. J., Farrelly, D., Black, C., \& Moore, H. (2007). Emotional intelligence, Machiavellianism and emotional manipulation: Does EI have a dark side? Personality and Individual Differences, 43, 179-189.

Badre, D., \& Wagner, A. D. (2007). Left ventrolateral prefrontal cortex and the cognitive control of memory. Neuropsychologia, 45, 2883 2901.

Bereczkei, T. (2015). The manipulative skill: Cognitive devices and their neural correlates underlying Machiavellian's decision making. Brain and Cognition, 99, 24-31. doi:10.1016/j.bandc.2015.06.007

Bereczkei, T., \& Birkas, B. (2014). The insightful manipulator: Machiavellians' interpersonal tactics may be linked to their superior information processing skills. International Journal of Psychological Studies, 6, 65-70.

Bereczkei, T., \& Czibor, A. (2014). Personality and situational factors differently influence high Mach and low Mach persons' decisions in a social dilemma game. Personality and Individual Differences, 64, 168-173.

Bereczkei, T., Deak, A., Papp, P., Perlaki, G., \& Orsi, G. (2013). Neural correlates of Machiavellian strategies in a social dilemma task. Brain and Cognition, 82, 108-116. doi:10.1016/j.bandc.2013.02.012

Bereczkei, T., Papp, P., Kincses, P., Bodrogi, B., Perlaki, G., Orsi, G., \& Deak, A. (2015). The neural basis of the Machiavellians' decision making in fair and unfair situations. Brain and Cognition, 98, 5364.

Botvinick, M. M., Cohen, J. D., \& Carter, C. S. (2004). Conflict monitoring and anterior cingulate cortex: An update. Trends in Cognitive Sciences, 8, 539-546. doi:10.1016/j.tics.2004.10.003

Buhle, J. T., Silvers, J. A., Wager, T. D., Lopez, R., Onyemekwu, C., Kober, H., \& Ochsner, K. N. (2014). Cognitive reappraisal of emotion: A meta-analysis of human neuroimaging studies. Cerebral Cortex, 24, 2981-2990.

Chang, L. J., Yarkoni, T., Khaw, M. W., \& Sanfey, A. G. (2013). Decoding the role of the insula in human cognition: Functional parcellation and large-scale reverse inference. Cerebral Cortex, 23, 739-749. doi:10.1093/cercor/bhs065

Christie, R., \& Geis, F. L. (1970). Studies in Machiavellianism. New York, NY: Academic Press.

Cona, G., Scarpazza, C., Sartori, G., Moscovitch, M., \& Bisiacchi, P. S. (2015). Neural bases of prospective memory: A meta-analysis and the "attention to delayed intention"(AtoDI) model. Neuroscience \& Biobehavioral Reviews, 52, 21-37.

Craig, A. D. (2009). How do you feel-now? the anterior insula and human awareness. Nature Reviews Neuroscience, 10, 59-70. doi:10.1038/nrn2555

Cunningham, W. A., \& Brosch, T. (2012). Motivational salience amygdala tuning from traits, needs, values, and goals. Current Directions in Psychological Science, 21, 54-59.

Cunningham, W. A., Van Bavel, J. J., \& Johnsen, I. R. (2008). Affective flexibility. Evaluative processing goals shape amygdala activity. Psychological Science, 19, 152-160.

Czibor, A., \& Bereczkei, T. (2012). Machiavellian people's success results from monitoring their partners. Personality and Individual Differences, 53, 202-206.
Deak, A., Csenki, L., \& Revesz, G. (2010). Hungarian ratings for the international affective picture system (IAPS): A cross-cultural comparison. Empirical Text and Culture Research, 4, 90-101.

Diekhof, E. K., Geier, K., Falkai, P., \& Gruber, O. (2011) Fear is only as deep as the mind allows. NeuroImage, 58(1), 275-285.

Etkin, A., Büchel, C., \& Gross, J. J. (2015). The neural bases of emotion regulation. Nature Reviews Neuroscience, 16, 693-700.

Frank, D. W., Dewitt, M., Hudgens-Haney, M., Schaeffer, D. J., Ball, B. H., Schwarz, N. F., \& Sabatinelli, D. (2014). Emotion regulation: Quantitative meta-analysis of functional activation and deactivation. Neuroscience \& Biobehavioral Reviews, 45, 202-211.

Geis, F., Weinheimer, S., \& Berger, D. (1970). Playing legislature: Cool heads and hot issues. In R. Christie \& F. Geis (Eds.), Studies in Machiavellianism (pp. 190-209). New York, NY: Academic Press.

Goldin, P. R., McRae, K., Ramel, W., \& Gross, J. J. (2008). The neural bases of emotion regulation: Reappraisal and suppression of negative emotion. Biological Psychiatry, 63, 577-586.

Griffiths, P. E. (2003). Basic emotions, complex emotions, Machiavellian emotions. Royal Institute of Philosophy Supplement, 52, 39-67.

Griffiths, P. E. (2004). Toward a Machiavellian theory of emotional appraisal. In D. Evans \& P. Cruse (Eds.), Emotion, evolution, and rationality (pp. 89-105). Oxford, UK: Oxford University Press.

Gross, J. J. (1998). The emerging field of emotion regulation: An integrative review. Review of General Psychology, 2, 271-299. doi:10.1037/1089-2680.2.3.271

Gross, J. J. (2002). Emotion regulation: Affective, cognitive, and social consequences. Psychophysiology, 39, 281-291.

Gross, J. J. (2014). Emotion regulation: Conceptual and empirical foundations. In J. J. Gross (Ed.), Handbook of emotion regulation (2nd ed., pp. 3-20). New York, NY: Guilford.

Hamann, S. (2001). Cognitive and neural mechanisms of emotional memory. Trends in Cognitive Sciences, 5, 394-400.

Harenski, C. L., Kim, S. H., \& Hamann, S. (2009). Neuroticism and psychopathy predict brain activation during moral and nonmoral emotion regulation. Cognitive, Affective, \& Behavioral Neuroscience, 9, 1-15. doi:10.3758/CABN.9.1.1

Hariri, A. R., \& Whalen, P. J. (2011). The amygdala: Inside and out. F1000 Biology Reports, 14, 2.

Hermann, A., Bieber, A., Keck, T., Vaitl, D., \& Stark, R. (2014). Brain structural basis of cognitive reappraisal and expressive suppression. Social Cognitive and Affective Neuroscience, 9, 1435-1442. doi:10.1093/scan/nst130

Jackson, D. C., Malmstadt, J. R., Larson, C. L., \& Davidson, R. J. (2000). Suppression and enhancement of emotional responses to unpleasant pictures. Psychophysiology, 37, 515-522.

Jones, D. N., \& Paulhus, D. L. (2009). Machiavellianism. In M. R. Leary \& R. H. Hoyle (Eds.), Individual differences in social behavior (pp. 93-108). New York, NY: Guilford Press.

Kim, H., Daselaar, S. M., \& Cabeza, R. (2010) Overlapping brain activity between episodic memory encoding and retrieval: Roles of the taskpositive and task-negative networks. NeuroImage, 49(1), 10451054.

Knutson, B., \& Cooper, J. C. (2005). Functional magnetic resonance imaging of reward prediction. Current Opinion in Neurology, 18, 411-417.

Kohn, N., Eickhoff, S. B., Scheller, M., Laird, A. R., Fox, P. T., \& Habel, U. (2014). Neural network of cognitive emotion regulation-An ALE meta-analysis and MACM analysis. NeuroImage, 87, 345355.

Lang, P. J., Bradley, M. M., \& Cuthbert, B. N. (2005). International Affective Picture System (IAPS): Affective ratings of pictures and instruction manual (Technical Report A-6). Gainesville, FL: University of Florida, Center for Research in Psychophysiology.

Lee, H., Heller, A. S., van Reekum, C. M., Nelson, B., \& Davidson, R. J. (2012). Amygdala-prefrontal coupling underlies individual differences in emotion regulation. NeuroImage, 62, 1575-1581. 
Leech, R., Kamourieh, S., Beckmann, C. F., \& Sharp, D. J. (2011). Fractionating the default mode network: Distinct contributions of the ventral and dorsal posterior cingulate cortex to cognitive control. Journal of Neuroscience, 31, 3217-3224.

Leech, R., \& Sharp, D. J. (2014). The role of the posterior cingulate cortex in cognition and disease. Brain, 137, 12-32.

Lyons, M., Caldwell, T., \& Shultz, S. (2010). Mind-reading and manipulation-Is Machiavellianism related to theory of mind? Journal of Evolutionary Psychology, 8, 261-274. doi:10.1556/JEP.8.2010.3.7

Maddock, R. J. (1999). The retrosplenial cortex and emotion: New insights from functional neuroimaging of the human brain. Trends in Neurosciences, 22, 310-316.

Maddock, R. J., Buonocore, M. H., Kile, S. J., \& Garrett, A. (2003). Brain regions showing increased activation by threat-related words in panic disorder. NeuroReport, 14, 325-328.

Mcllwain, D. (2003). Bypassing empathy: A Machiavellian theory of mind and sneaky power. In B. Repacholi \& V. Slaughter (Eds.), Individual differences in theory of mind (pp. 39-66). Hove, UK: Psychology Press.

Miller, E. K., \& Cohen, J. D. (2001). An integrative theory of prefrontal cortex function. Annual Review of Neuroscience, 24, 167-202. doi:10.1146/annurev.neuro.24.1.167

Molenberghs, P., Johnson, H., Henry, J. D., \& Mattingley, J. B. (2016). Understanding the minds of others: A neuroimaging meta-analysis. Neuroscience \& Biobehavioral Reviews, 65, 276-291.

Monaghan, C., Bizumic, B., \& Sellbom, M. (2016). The role of Machiavellian view and tactics in psychopathology. Personality and Individual Differences, 94, 72-81.

Nagler, U. K. J., Reiter, K. J., Furtner, M. R., \& Rauthmann, J. F. (2014). Is there a "dark intelligence"? emotional intelligence is used by dark personalities to emotionally manipulate others. Personality and Individual Differences, 65, 47-52.

Neria, A. L., Vizcaino, M., \& Jones, D. N. (2016). Approach/avoidance tendencies in dark personalities. Personality and Individual Differences, 101, 264-269.

O'Connor, P. J., \& Athota, V. S. (2013). The intervening role of agreeableness in the relationship between trait emotional intelligence and Machiavellianism: Reassessing the potential dark side of EI. Personality and Individual Differences, 55, 750-754.

O'Doherty, J. P. (2004). Reward representations and reward-related learning in the human brain: Insights from neuroimaging. Current Opinion in Neurobiology, 14, 769-776.

Ochsner, K. N., Ray, R. D., Cooper, J. C., Robertson, E. R., Chopra, S., Gabrieli, J. D. E., \& Gross, J. J. (2004). For better or for worse: Neural systems supporting the cognitive down- and up-regulation of negative emotion. NeuroImage, 23, 483-499. doi:10.1016/j. neuroimage.2004.06.030

Ochsner, K. N., Silvers, J. A., \& Buhle, J. T. (2012). Functional imaging studies of emotion regulation: A synthetic review and evolving model of the cognitive control of emotion. Annals of the New York Academy of Sciences, 1251, E1-E24.

Paal, T., \& Bereczkei, T. (2007). Adult theory of mind, cooperation, Machiavellianism: The effect of mindreading on social relations. Personality and Individual Differences, 43, 541-551.

Pearson, J. M., Heilbronner, S. R., Barack, D. L., Hayden, B. Y., \& Platt, M. L. (2011). Posterior cingulate cortex: Adapting behavior to a changing world. Trends in Cognitive Sciences, 15, 143-151.

Phan, K. L., Wager, T., Taylor, S. F., \& Liberzon, I. (2002). Functional neuroanatomy of emotion: A meta-analysis of emotion activation studies in PET and fMRI. NeuroImage, 16, 331-348. doi:10.1006 /nimg.2002.1087

Pilch, I. (2008). Machiavellianism, emotional intelligence, and social competence: Are Machiavellians interpersonally skilled? Polish Psychological Bulletin, 39, 158-164.

Puetz, V. B., Viding, E., Palmer, A., Kelly, P. A., Lickley, R., Koutoufa, I., \& McCrory, E. J. (2016). Altered neural response to rejection-related words in children exposed to maltreatment. Journal of Child Psychology and Psychiatry, 57, 1165-1173. doi:10.1111 /jcpp. 12595

Roy, M., Shohamy, D., \& Wager, T. D. (2012). Ventromedial prefrontalsubcortical systems and the generation of affective meaning. Trends in Cognitive Sciences, 16, 147-156.

Sato, W., Kochiyama, T., Yoshikawa, S., Naito, E., \& Matsumura, M. (2004). Enhanced neural activity in response to dynamic facial expressions of emotion: An fMRI study. Cognitive Brain Research, 20, 81-91.

Simon, I., Williams, T., Wolfe, M., \& Hessler, J. (2015). I can't remember: The effects of Machiavellianism, mental effort and lying on memory. Student Summer Scholars, 137. Retireved from scholarworks.gvsu.edu/sss/137/

Spitzer, M., Fischbacher, U., Herrnberger, B., Grön, G., \& Fehr, E. (2007). The neural signature of social norm compliance. Neuron, 56, 185-196.

Szabo, E., Jones, D. N., \& Bereczkei, T. (2016). Dark Triad and theory of mind: Mentalization as a device of manipulation for Machiavellians. Manuscript under review.

Szijjarto, L., \& Bereczkei, T. (2015). The Machiavellians' "cool syndrome": They experience intensive feelings but have difficulties in expressing their emotions. Current Psychology, 34, 363-375.

Tan, Y., Zhang, Q., Li, W., Wei, D., Qiao, L., Qiu, J., \& Liu, Y. (2014). The correlation between emotional intelligence and gray matter volume in university students. Brain and Cognition, 91, 100-107.

Thompson, R. A. (1994). Emotion regulation: The main search of definition. Monographs of the Society for Research in Child Development, 59, 25-52.

Thompson-Schill, S. L., Bedny, M., \& Goldberg, R. F. (2005). The frontal lobes and the regulation of mental activity. Current Opinion in Neurobiology, 15, 219-224. doi:10.1016/j.conb.2005.03.006

Trost, W., \& Frühholz, S. (2015). The hippocampus is an integral part of the temporal limbic system during emotional processing: Comment on "the quartet theory of human emotions: An integrative and neurofunctional model" by S. Koelsch et al. Physics of Life Reviews, 13, 87-88.

Tune, S., \& Asaridou, S. S. (2016). Stimulating the semantic network: What can TMS tell us about the roles of the posterior middle temporal gyrus and angular gyrus? Journal of Neuroscience, 36, 44054407.

Van Reekum, C. M., Johnstone, T., Urry, H. L., Thurow, M. E., Schaefer, H. S., Alexander, A. L., \& Davidson, R. J. (2007). Gaze fixations predict brain activation during the voluntary regulation of pictureinduced negative affect. NeuroImage, 36, 1041-1055.

Veit, R., Singh, V., Sitaram, R., Caria, A., Rauss, K., \& Birbaumer, N. (2012). Using real-time fMRI to learn voluntary regulation of the anterior insula in the presence of threat-related stimuli. Social Cognitive and Affective Neuroscience, 7, 623-634.

Verbeke, W. J. M. I., Rietdijk, W. J. R., van den Berg, W. E., Dietvorst, R. C., Worm, L., \& Bagozzi, R. P. (2011). The making of the Machiavellian brain: A structural MRI analysis. Journal of Neuroscience, Psychology, and Economics, 4, 205-216. doi:10.1037/a0025802

Vetter, N. C., Pilhatsch, M., Weigelt, S., Ripke, S., \& Smolka, M. N. (2015). Mid-adolescent neurocognitive development of ignoring and attending emotional stimuli. Developmental Cognitive Neuroscience, 14, 23-31.

Wager, T. D., Davidson, M. L., Hughes, B. L., Lindquist, M. A., \& Ochsner, K. N. (2008). Prefrontal-subcortical pathways mediating successful emotion regulation. Neuron, 59, 1037-1050. doi:10.1016 /j.neuron.2008.09.006

Wai, M., \& Tiliopoulos, N. (2012). The affective and cognitive empathic nature of the dark triad of personality. Personality and Individual Differences, 52, 794-799. 
Wallentin, M., Nielsen, A. H., Vuust, P., Dohn, A., Roepstorff, A., \& Lund, T. E. (2011). BOLD response to motion verbs in left posterior middle temporal gyrus during story comprehension. Brain and Language, 119, 221-225.

Wastell, C., \& Booth, A. (2003). Machiavellianism: An alexithymic perspective. Journal of Social and Clinical Psychology, 22, 730-744.
Wilson, D. S., Near, D., \& Miller, R. R. (1996). Machiavellianism: A synthesis of the evolutionary and psychological literatures. Psychological Bulletin, 119, 285-299.

Zaki, J., Davis, J. I., \& Ochsner, K. N. (2012). Overlapping activity in anterior insula during interoception and emotional experience. NeuroImage, 62, 493-499. doi:10.1016/j.neuroimage.2012.05.012. 